\title{
Composição e fungitoxicidade do óleo essencial de capim citronela em função da adubação orgânica
}

\author{
Ronice Alves Veloso(1), Henrique Guilhon de Castro(1), Dione Pereira Cardoso(1), Gil Rodrigues dos Santos ${ }^{(1)}$, \\ Luiz Cláudio de Almeida Barbosa ${ }^{(2)}$ e Kamilla Pires da Silva(1)
}

(1)Universidade Federal do Tocantins, Campus de Gurupi, Rua Badejós, Chácaras 69 a 72, Zona Rural, Caixa Postal 66, CEP 77402-970 Gurupi, TO. E-mail: ronicealves@hotmail.com, hguilhon@uft.edu.br, cardoso.dione@gmail.com, gilrsan@uft.edu.br, kamilla_pires1@hotmail.com (2)Universidade Federal de Viçosa, Departamento de Química, Campus de Viçosa, Centro, CEP 36571-000 Viçosa, MG. E-mail: Icab@ufv.br

Resumo - O objetivo deste trabalho foi avaliar a influência da adubação orgânica sobre o teor e a composição do óleo essencial de capim citronela (Cymbopogon nardus), bem como a fungitoxicidade desse óleo ao crescimento micelial dos fungos Didymella bryoniae, Colletotrichum gloeosporioides e Amphobotrys ricini. A extração do óleo essencial foi realizada por hidrodestilação, a partir de plantas cultivadas em quatro doses de adubação orgânica $(0,3,6$ e $9 \mathrm{~kg}$ de esterco bovino curtido por cova), e a identificação dos constituintes químicos foi conduzida por cromatografia gasosa/espectrometria de massas. Para avaliar a inibição do crescimento micelial, o experimento foi instalado no delineamento inteiramente casualizado, em arranjo fatorial. Foram testadas sete alíquotas do óleo essencial $(0,5,10,15,20,25$ e $30 \mu \mathrm{L})$, em cinco épocas de avaliação, com quatro repetições. O teor de óleo essencial do capim citronela não foi afetado pela adubação orgânica, e o óleo essencial do capim citronela apresentou 24 compostos químicos, entre estes monoterpenos e sesquiterpenos, com maior concentração dos compostos citronelal, $\beta$-citronelol, geraniol e elemol. O óleo essencial do capim citronela apresenta maior efeito de inibição a Amphobotrys ricini, em comparação aos fungos Didymella bryoniae e Colletotrichum gloeosporioides.

Termos para indexação: Cymbopogon nardus, bioatividade, óleo essencial, plantas medicinais.

\section{Composition and fungitoxicity of essential oil of citronella grass as affected by organic fertilization}

\begin{abstract}
The objective of this work was to evaluate the influence of organic fertilization on the content and composition of the essential oil of citronella grass (Cymbopogon nardus), as well as to assess the fungitoxicity of this oil to the mycelial growth of the fungi Didymella bryoniae, Colletotrichum gloeosporioides, and Amphobotrys ricini. The extraction of the essential oil was done by hydrodistillation in plants cultivated with four doses of organic fertilizer $(0,3,6$, and $9 \mathrm{~kg}$ matured cattle manure per hole), and the identification of the chemical compounds was done by gas chromatography/mass spectroscopy. To evaluate the inhibition of mycelial growth, the experiment was installed in a completely randomized design in a factorial arrangement. Seven aliquots of essential oil were tested $(0,5,10,15,20,25$, and $30 \mu \mathrm{L})$ in five evaluating times, with four replicates. The contents of the essencial oil in citronella grass were note affected by organic fertilization, and the oil includes 24 chemical compounds, among these monoterpenes and sesquiterpenes, with higher concentrations of the compounds citronellal, $\beta$-citronellol, geraniol, and elemol. The essential oil of citronella grass has higher inhibition effect on Amphobotrys ricini, when compared to the fungi Didymella bryoniae e Colletotrichum gloeosporioides.
\end{abstract}

Index terms: Cymbopogon nardus, bioactivity, essential oil, medicinal plants.

\section{Introdução}

A adubação orgânica representa boa opção para a maximização da produção de princípios ativos e do rendimento de fitomassa de espécies medicinais (Brant et al., 2010). Estudos sobre o rendimento de biomassa e óleo essencial em resposta à adubação orgânica, mineral e mista vêm sendo desenvolvidos com espécies medicinais, como Ocimum basilicum L. (Blank et al., 2005), Ocimum selloi Benth. (Gonçalves et al., 2003; Costa et al., 2008) e Justicia pectoralis Jacq. (Bezerra et al., 2006). Sales et al. (2009) verificaram maiores rendimentos de óleo essencial, com adubação orgânica, em cultivos de Hyptis marrubioides Epling.

Autilização de óleos essenciais ou extratos botânicos no controle fitossanitário tem sido frequentemente 
relatada. Diversos trabalhos com óleos essenciais têm indicado o seu potencial no controle de bactérias (Silva et al., 2010; Demuner et al., 2011; Nascimento et al., 2011) e de fungos fitopatogênicos. A inibição do desenvolvimento de fungos pode ser atribuída tanto a sua ação direta, que inibe o crescimento micelial e a germinação de esporos, quanto à indução de resistência a diversos patógenos (Schwan-Estrada et al., 2003; Donlaporn \& Suntornsuk, 2010; Deus et al., 2011; Perini et al., 2011; Seixas et al., 2011; Garcia et al., 2012; Passos et al., 2012). Nas bactérias, o mecanismo de ação pode ocorrer, em alguns casos, pela ação oxidante dos constituintes dos óleos, o que resulta em danificação da membrana celular (Montanari net al., 2012).

Capim citronela é um nome comum para as espécies Cymbopogon citratus (D.C.) Stapf e Cymbopogon nardus (L.) Rendle. Essas plantas são originárias da Índia e são utilizadas, por exemplo, como chá calmante e digestivo, na Indonésia (Castro et al., 2007, 2010), e como sedativos e calmantes na medicina popular, no Brasil. Os óleos essenciais produzidos por C. nardus e C. citratus apresentam alto teor de geraniol e citronelal (Barbosa et al., 2008). O citronelal é utilizado como material básico para a síntese de importantes compostos químicos, denominados iononas, que são precursores e sintéticos para a obtenção de vitamina A. Esse óleo apresenta atividade repelente a insetos e ação fungicida e bactericida, além de ser utilizado na fabricação de perfumes e cosméticos (Trongtokit et al., 2005; Wong et al., 2005; Reis et al., 2006).

O objetivo deste trabalho foi avaliar a influência da adubação orgânica sobre o teor e a composição do óleo essencial do capim citronela (Cymbopogon nardus), bem como a fungitoxicidade desse óleo ao crescimento micelial dos fungos Didymella bryoniae, Colletotrichum gloeosporioides e Amphobotrys ricini.

\section{Material e Métodos}

A extração do óleo essencial foi realizada em plantas de capim citronela cultivadas em área experimental do campus universitário de Gurupi, da Universidade Federal do Tocantins $\left(11^{\circ} 43^{\prime} 45^{\prime \prime} \mathrm{S}\right.$ e $49^{\circ} 04^{\prime} 07^{\prime \prime} \mathrm{W}$, a $300 \mathrm{~m}$ de altitude média), em 2009. Segundo Thornthwaite, o clima é do tipo B1wA'a', úmido e com moderada deficiência hídrica (Atlas do Tocantins, 2003).

O solo da área experimental foi classificado como Latossolo Vermelho-Amarelo distrófico de textura média. A análise química do solo, na área experimental, indicou: $\mathrm{pH}\left(\mathrm{H}_{2} \mathrm{O}\right) 5,6 ; 1,5 \mathrm{cmol}_{\mathrm{c}} \mathrm{dm}^{-3} \mathrm{de}^{+}+\mathrm{Al}^{+++}$; 1,4 cmol $_{\mathrm{c}} \mathrm{dm}^{-3}$ de $\mathrm{Ca}^{++} ; 0,1 \mathrm{cmol}_{\mathrm{c}} \mathrm{dm}^{-3}$ de $\mathrm{Mg}^{++}$; $0,9 \mathrm{mg} \mathrm{dm}^{-3}$ de $\mathrm{P}$ (extrator Melich 1); 4,6mg dm${ }^{-3}$ de $\mathrm{K}^{+} ; 9,6 \mathrm{~g} \mathrm{dm}^{-3}$ de matéria orgânica; CTC de $3,0 \mathrm{cmol}_{\mathrm{c}} \mathrm{dm}^{-3}$; e saturação por bases de $50,8 \%$.

A exsicata, com amostra do material vegetal, foi depositada no herbário da Universidade Federal de Viçosa, identificada pelo número VIC 30283.

As plantas do capim citronela foram cultivadas com quatro doses de adubação orgânica $(0,3,6$ e 9 kg de esterco bovino curtido por cova) e colhidas 192 dias após o transplante para a extração do óleo essencial. O óleo essencial foi obtido por hidrodestilação, a partir de amostras da parte aérea da planta, desidratadas e cortadas $(0,03 \mathrm{~kg})$, por um período de 2 horas, com cinco repetições. As amostras foram colocadas em balão de fundo redondo, contendo $1 \mathrm{~L}$ de água destilada, acoplado a aparelho tipo Clevenger, ligado a um condensador.

O óleo essencial foi extraído da fase aquosa, tendose utilizado pentano $(3 \times 50 \mathrm{~mL})$. As frações orgânicas obtidas foram reunidas, secadas com sulfato de magnésio anidro e filtradas, e o solvente foi removido sob pressão reduzida, em evaporador rotativo, modelo Q344B2 (Quimis, Diadema, SP), a $40^{\circ} \mathrm{C}$.

A identificação dos compostos do óleo essencial foi feita pelo cromatógrafo gasoso, modelo GC 17A (Shimadzu do Brasil, São Paulo, SP), com detector seletivo de massa, modelo QP 5050A (Shimadzu do Brasil, São Paulo, SP). A coluna cromatográfica utilizada foi do tipo capilar de sílica fundida, com fase estacionária $\mathrm{GC} 10$, de $30 \mathrm{~m}$ de comprimento e $0,22 \mathrm{~m}$ de diâmetro interno, com filme de $0,25 \mu \mathrm{m}$. Foi utilizado hélio como gás carreador, com a velocidade de $1,8 \mathrm{~mL}$ por min. As temperaturas foram de $220^{\circ} \mathrm{C}$, no injetor, e $240^{\circ} \mathrm{C}$, no detector. A temperatura do forno foi programada de 40 a $180^{\circ} \mathrm{C}$, com acréscimo de $3^{\circ} \mathrm{C}$ a cada $60 \mathrm{~s}$. A temperatura inicial foi de $40^{\circ} \mathrm{C}$ por 4 min, seguido de incremento de $3^{\circ} \mathrm{C}$ por 1 min até atingir temperatura de $180^{\circ} \mathrm{C}$, mantida constante por $50 \mathrm{~min}$.

A identificação dos constituintes químicos foi feita por comparação dos espectros de massas obtidos com 
os espectros de massas disponíveis no banco de dados do equipamento, com base na literatura e com uso do índice aritmético de retenção (Adams, 2007).

Os dados do teor de óleo essencial foram interpretados por meio de análise de variância, e as médias foram comparadas pelo teste de Tukey, a 5\% de probabilidade.

O óleo essencial foi obtido por hidrodestilação, a partir de amostras da parte aérea da planta desidratada $(0,03 \mathrm{~kg})$, oriunda do cultivo do capim citronela com 9 kg de adubação orgânica por cova (dose de adubação orgânica que propiciou maior produção de biomassa), e colhida 192 dias após transplante. O óleo essencial utilizado, neste experimento, foi constituído pelo sobrenadante do líquido resultante da hidrodestilação, por um período de 2 horas.

Foram utilizados isolados de Didymella bryoniae [(Auersw.) Rehm 1881] (cultura do pepino), Colletotrichum gloeosporioides [(Penz.) Penz. \& Sacc. 1884] (cultura do caju) e Amphobotrys ricini [(N.F. Buchw.) Hennebert 1973] (cultura da mamona). O isolado de C. gloeosporioides, da cultura do caju, foi obtido de plantas que exibiam sintomas típicos da doença, cultivadas em área experimental do campus de Gurupi, TO. Os isolados de D. bryoniae e A. ricini foram obtidos da coleção de fungos do Laboratório de Patologia de Sementes da Universidade Federal de Lavras.

Para o isolamento de C. gloeosporioides, utilizou-se o meio batata-dextrose-agar (BDA) em placas de Petri. Fragmentos de folhas, com sintomas, previamente desinfetadas em hipoclorito de sódio $1,5 \%$, foram transferidos para as placas de Petri e, posteriormente, incubados a $25^{\circ} \mathrm{C}$ por sete dias.

Para avaliar a inibição do crescimento micelial, o experimento foi instalado no delineamento inteiramente casualizado, em arranjo fatorial, com quatro repetições. Os tratamentos foram compostos por sete alíquotas de óleo essencial $(0,5,10,15,20,25$ e $30 \mu \mathrm{L})$ e cinco épocas de avaliação $(2,4,6,8$ e 10 dias após a repicagem).

O óleo essencial foi distribuído uniformemente sobre o meio de cultura BDA em placas de Petri $(90 \mathrm{~mm})$, com auxílio de alça de Drigalski. Em seguida, no centro de cada placa, foi depositado um disco de $0,8 \mathrm{~cm}$ de diâmetro do meio BDA, contendo micélio do fungo com sete dias. As placas foram vedadas com fita $\mathrm{PVC}$, identificadas e incubadas a $25^{\circ} \mathrm{C}$. A partir da incubação, foi mensurado o diâmetro médio das colônias a cada dois dias, por meio da medição, em dois sentidos diametralmente opostos, até dez dias após a repicagem.

Os dados foram interpretados por meio de análises de variância e de regressão. As médias foram comparadas pelo teste de Tukey, a 5\% de probabilidade. As equações de regressão foram ajustadas com base no teste $\mathrm{t}$ dos coeficientes, a 5 ou $1 \%$ de probabilidade, e no coeficiente de determinação. As análises estatísticas foram feitas no programa SAEG (Ribeiro Júnior \& Melo, 2009).

\section{Resultados e Discussão}

Não foram observadas diferenças significativas entre os valores de teor de óleo essencial para as plantas cultivadas com diferentes doses de adubo orgânico (Tabela 1). Corrêa et al. (2010) verificaram, em plantas de orégano (Origanum vulgare L.), efeito significativo entre dosagens de adubo orgânico, o que evidencia que, à medida que aumentaram as doses de esterco bovino, aumentou o teor de óleo essencial.

A análise do óleo por cromatografia gasosa e espectrometria de massas resultou na identificação de 24 substâncias (Tabela 1). Para fins de apresentação, os compostos foram listados nos seguintes grupos: monoterpenos hidrocarbonetos; monoterpenos oxigenados; sesquiterpenos hidrocarbonetos; sesquiterpenos oxigenados; e outras classes de compostos. Constatouse que, em todos os tratamentos, os monoterpenos foram os constituintes majoritários dos óleos, seguidos dos sesquiterpenos. Para os óleos obtidos de plantas cultivadas com a dose de $6 \mathrm{~kg}$ por cova, foi obtida a maior concentração relativa de monoterpenos $(89,62 \%)$, e a maior concentração de compostos sesquiterpênicos $(7,57 \%)$ foi observada para os óleos obtidos do tratamento com a dose de $9 \mathrm{~kg}$ por cova.

Em todas as amostras, foram identificados quatro compostos majoritários: três monoterpenos (citronelal, $\beta$-citronelol e geraniol) e um sesquiterpeno (elemol). Para as amostras obtidas dos tratamentos sem adubação e com $3 \mathrm{~kg}$ por cova, o sesquiterpeno $\beta$-Elemeno também foi obtido em quantidades expressivas de 3,62 e $4 \%$, respectivamente. Nos tratamentos com doses mais elevadas de adubação, os teores aproximados desse composto foram de $1 \%$. Nas doses de adubação orgânica de 0,3 e $9 \mathrm{~kg}$ por cova, o geraniol foi o 
composto com maior concentração relativa, enquanto, na dose de $6 \mathrm{~kg}$ por cova de adubo orgânico, o composto majoritário foi o citronelal (Tabela 1).

Para C. nardus, resultados semelhantes foram obtidos por Koffi et al. (2009), que identificaram o citronelal, o geraniol e o citronelol como constituintes majoritários; e por Mahalwal \& Ali (2003), que detectaram o citronelal, o geraniol, o $\gamma$-terpineol e o hidrato de cis-sabineno. Castro et al. (2010) encontraram, na mesma espécie, os compostos majoritários citronelol, geraniol e elemol, e Singh et al. (2011) identificaram o $\alpha$-t-bergamoteno, o valenceno e o $\delta$-cadineno. Essa diferença na composição química constatada por diferentes autores pode estar relacionada a fatores ambientais, genéticos e fenológicos (Castro et al., 2004; Martins et al., 2006). Dessa forma, para se entender melhor as variações observadas no presente trabalho, todas

Tabela 1. Concentração relativa (área, \%), obtida por cromatografia gasosa e espectrometria de massas, dos constituintes do óleo essencial da parte aérea de Cymbopogon nardus, cultivado sob quatro doses de adubo orgânico de esterco bovino curtido, em $2012^{(1)}$.

\begin{tabular}{|c|c|c|c|c|c|c|}
\hline \multirow[t]{2}{*}{ Constituintes } & \multirow[t]{2}{*}{ Pico } & \multirow[t]{2}{*}{ Índice aritmético } & \multicolumn{4}{|c|}{ Doses de adubo orgânico (kg por cova) } \\
\hline & & & 0 & 3 & 6 & 9 \\
\hline \multicolumn{7}{|c|}{ Monoterpos hidrocarbonetos } \\
\hline$\beta$-Mirceno & 2 & 990 & 0,12 & 0,11 & 0,20 & 0,13 \\
\hline Limoneno & 4 & 1025 & 4,74 & 5,32 & 9,44 & 5,38 \\
\hline Subtotal & & & 4,86 & 5,43 & 9,64 & 5,51 \\
\hline \multicolumn{7}{|l|}{ Monoterpenos oxigenados } \\
\hline Bergamal & 5 & 1051 & 0,57 & 0,51 & 1,05 & 0,62 \\
\hline Linalol & 6 & 1098 & 1,72 & 1,60 & 2,89 & 1,49 \\
\hline cis-Óxido de rosa & 7 & 1107 & 0,23 & 0,27 & 0,45 & 0,20 \\
\hline Isopulegol & 8 & 1141 & 1,46 & 1,18 & 2,07 & 1,38 \\
\hline Citronelal & 9 & 1151 & 23,22 & 17,80 & 34,87 & 24,86 \\
\hline$\beta$-Citronelol & 10 & 1230 & 14,20 & 14,82 & 13,96 & 13,86 \\
\hline Geraniol & 11 & 1259 & 33,68 & 35,43 & 21,83 & 33,36 \\
\hline Formato de citronelila & 12 & 1275 & 0,28 & 0,87 & 0,45 & 0,27 \\
\hline Formato de geranila & 13 & 1300 & 0,19 & 0,62 & 0,49 & 0,26 \\
\hline Acetato de citronelila & 14 & 1355 & 2,32 & 2,44 & 1,88 & 2,01 \\
\hline Acetato de geranila & 15 & 1386 & 2,45 & 0,23 & 0,06 & 0,13 \\
\hline Subtotal & & & 80,31 & 75,76 & 79,98 & 78,43 \\
\hline \multicolumn{7}{|c|}{ Sesquiterpenos hidrocarbonetos } \\
\hline$\beta$-Elemeno & 16 & 1388 & 3,62 & 4,00 & 1,15 & 0,91 \\
\hline$\delta$-Cadineno & 17 & 1517 & 0,37 & 0,35 & 0,29 & 0,45 \\
\hline Subtotal & & & 3,99 & 4,35 & 1,44 & 1,37 \\
\hline \multicolumn{7}{|l|}{ Sesquiterpenos oxigenados } \\
\hline Elemol & 18 & 1547 & 3,62 & 4,47 & 1,10 & 4,26 \\
\hline Germacreno-D-4-ol & 19 & 1569 & 0,15 & 0,32 & 0,06 & 0,37 \\
\hline$\gamma$-Eudesmol & 20 & 1625 & 0,23 & 0,36 & 0,13 & 0,13 \\
\hline Epi-alfa-Murolol & 21 & 1636 & 0,60 & 0,61 & 0,12 & 0,59 \\
\hline$\beta$-Eudesmol & 22 & 1643 & 0,42 & 0,54 & 0,08 & 0,56 \\
\hline$\alpha$-Eudesmol & 23 & 1647 & 0,41 & 0,66 & 0,08 & 0,55 \\
\hline$\alpha$-Cadinol & 24 & 1649 & 0,92 & 1,17 & 0,16 & 1,12 \\
\hline Subtotal & & & 6,37 & 8,14 & 1,72 & 7,57 \\
\hline \multicolumn{7}{|l|}{ Outros } \\
\hline 6-Metilept-5-en-2-ona & 1 & 987 & 0,09 & 0,18 & 0,33 & 0,12 \\
\hline 6-Metilept-5-en-2-ol & 3 & 994 & 0,20 & 0,29 & 0,39 & 0,19 \\
\hline Subtotal & & & 0,28 & 0,47 & 0,71 & 0,31 \\
\hline Total identificado & & & 95,82 & 94,15 & 93,51 & 93,19 \\
\hline Teor de óleo (\%) & & & $0,87 \mathrm{a}$ & $0,84 \mathrm{a}$ & $0,79 \mathrm{a}$ & $0,90 \mathrm{a}$ \\
\hline
\end{tabular}

${ }^{(1)}$ Médias seguidas de letras iguais, nas linhas, na variável teor de óleo, não diferem entre si, pelo teste de Tukey, a 5\% de probabilidade. 
as espécies previamente investigadas deveriam ser cultivadas e analisadas em condições iguais e controladas.

O óleo essencial do capim citronela teve maior efeito de inibição em $A$. ricini, quando comparado aos outros fungos avaliados, e não foi observado crescimento micelial com nenhuma das alíquotas testadas (5 a $30 \mu \mathrm{L})$.

O óleo essencial do capim citronela inibiu o crescimento micelial de C. gloeosporioides em todas as alíquotas testadas. À medida que se aumentou a alíquota utilizada, elevou-se o efeito de inibição do crescimento micelial. A alíquota de $30 \mu \mathrm{L}$ propiciou o maior efeito de inibição do crescimento micelial, tendo atingido o valor de 3,32 mm na última avaliação (Tabela 2). Na alíquota de $30 \mu \mathrm{L}$, não houve ajuste para nenhum modelo de regressão, e, nas demais alíquotas, foram ajustados modelos lineares.

Ao avaliar o efeito fungitóxico do óleo essencial de C. citratus sobre C. gloeosporioides, nas concentrações de 1, 3, 5 e $10 \mu \mathrm{L}$, Souza Júnior et al. (2009) observaram $100 \%$ de inibição do crescimento micelial.

Não houve crescimento micelial de $D$. bryoniae nas alíquotas maiores que $10 \mu \mathrm{L}$. Esta alíquota apresentou taxa de crescimento micelial de $3,99 \mathrm{~mm}$ por dia, tendo atingido, na última época de avaliação, 27,16 mm (Tabela 2).
Fiori et al. (2000), ao estudar os óleos essenciais de Eucalyptus citriodora Hook., C. citratus e Ageratum conyzoides L., verificaram $100 \%$ de inibição do crescimento micelial de $D$. bryoniae nas alíquotas testadas $(20,40,60,100,200,500$ e $1.000 \mu \mathrm{L})$.

Os óleos essenciais atuam na parede celular dos fungos, o que causa o vazamento do conteúdo celular (Amaral \& Bara, 2005). O efeito sobre as paredes celulares pode estar associado à oxidação de lipídios da membrana celular induzida por alguns dos constituintes do óleo (Montanari et al., 2012). Rasooli et al. (2006), ao usar microscopia eletrônica de transmissão, também constataram que o óleo essencial de Thymus eriocalyx (Ronniger) Jalas promoveu danos severos nas paredes, nas membranas e nas organelas celulares de Aspergillus niger Tiegh. (1867).

Outros experimentos com o uso de óleos essenciais e de constituintes do óleo essencial de C. nardus, no controle de fitopatógenos, devem ser realizados para potencializar a atividade antifúngica e verificar se o efeito sinergístico é determinante da bioatividade. O estudo da bioatividade de compostos orgânicos produzidos pelas plantas contribui para o avanço tecnológico, a partir da descoberta de novos princípios ativos.

Tabela 2. Valores médios e equações de regressão do crescimento micelial dos fungos Didymella bryoniae e Colletotrichum gloeosporioides, com o uso de sete alíquotas do óleo essencial do capim citronela, em cinco épocas de avaliação, em $2012^{(1)}$.

\begin{tabular}{|c|c|c|c|c|c|c|c|}
\hline \multirow{2}{*}{$\begin{array}{l}\text { Alíquota óleo essencial } \\
(\mu \mathrm{L})\end{array}$} & \multicolumn{5}{|c|}{ Dias após a repicagem } & \multirow[t]{2}{*}{ Equações de regressão } & \multirow[t]{2}{*}{$\mathrm{R}^{2}$} \\
\hline & 2 & 4 & 6 & 8 & 10 & & \\
\hline \multicolumn{8}{|c|}{ Crescimento micelial de Colletotrichum gloeosporioides $(\mathrm{mm})$} \\
\hline 0 & $15,01 \mathrm{a}$ & $33,17 \mathrm{a}$ & $56,77 \mathrm{a}$ & $77,49 \mathrm{a}$ & $85,18 \mathrm{a}$ & $\hat{\mathrm{Y}}=-1,88+9,2325^{* *} \mathrm{EP}$ & 0,98 \\
\hline 5 & $6,21 \mathrm{~b}$ & $15,38 \mathrm{~b}$ & $27,50 \mathrm{~b}$ & $39,81 b$ & $49,22 b$ & $\hat{\mathrm{Y}}=-5,5053+5,5221 * * \mathrm{EP}$ & 0,98 \\
\hline 10 & $0 \mathrm{c}$ & $1,09 \mathrm{c}$ & $10,24 \mathrm{c}$ & $19,05 \mathrm{c}$ & $29,29 \mathrm{c}$ & $\hat{Y}=-11,1787+3,9199 * * E P$ & 0,88 \\
\hline 15 & $0 \mathrm{c}$ & $0 \mathrm{c}$ & $8,51 \mathrm{c}$ & $11,88 \mathrm{~d}$ & $19,18 \mathrm{~d}$ & $\hat{\mathrm{Y}}=-6,4475+2,3315^{* *} \mathrm{EP}$ & 0,87 \\
\hline 20 & $0 \mathrm{c}$ & $0 \mathrm{c}$ & $6,94 \mathrm{c}$ & $11,65 \mathrm{~d}$ & $17,68 \mathrm{~d}$ & $\hat{\mathrm{Y}}=-7,4313+2,4921 * * \mathrm{EP}$ & 0,90 \\
\hline 25 & $0 \mathrm{c}$ & $0 \mathrm{c}$ & $0 \mathrm{~d}$ & $3,79 \mathrm{e}$ & $7,88 \mathrm{e}$ & $\hat{\mathrm{Y}}=-3,4713+0,9536^{* *} \mathrm{EP}$ & 0,65 \\
\hline 30 & $0 \mathrm{c}$ & $0 \mathrm{c}$ & $0 \mathrm{~d}$ & $1,52 \mathrm{e}$ & $3,32 \mathrm{e}$ & $\hat{Y}=0,968$ & \\
\hline \multicolumn{8}{|c|}{ Crescimento micelial de Didymella bryoniae (mm) } \\
\hline 0 & $33,71 \mathrm{a}$ & $66,15 \mathrm{a}$ & $82,65 \mathrm{a}$ & $90,00 \mathrm{a}$ & $90,00 \mathrm{a}$ & $\hat{\mathrm{Y}}=31,5738+6,8214 * * \mathrm{EP}$ & 0,81 \\
\hline 5 & $7,67 \mathrm{~b}$ & $21,35 b$ & $38,94 b$ & $59,70 \mathrm{~b}$ & $76,01 b$ & $\hat{Y}=-11,7805+8,7523 * * E P$ & 0,84 \\
\hline 10 & $0,00 \mathrm{~b}$ & $0,00 \mathrm{c}$ & $7,64 \mathrm{c}$ & $16,45 \mathrm{c}$ & $31,76 \mathrm{c}$ & $\hat{\mathrm{Y}}=-12,8210+3,9983 * * \mathrm{EP}$ & 0,79 \\
\hline
\end{tabular}




\section{Conclusões}

1. O teor de óleo essencial não é afetado pela aduabação orgânica, e a composição do óleo essencial do capim citronela apresenta 24 compostos químicos, entre estes, monoterpenos e sesquiterpenos, com maior concentração dos compostos citronelal, $\beta$-Citronelol, geraniol e elemol.

2. O óleo essencial do capim citronela apresenta maior efeito de inibição de Amphobotrys ricini, em comparação aos fungos Didymella bryoniae e Colletotrichum gloeosporioides.

\section{Agradecimentos}

Ao Conselho Nacional de Desenvolvimento Científico e Tecnológico $(\mathrm{CNPq})$ e à Coordenação de Aperfeiçoamento de Pessoal de Nível Superior (Capes), pela concessão de bolsas; e à Fundação de Amparo à Pesquisa do Estado de Minas Gerais (Fapemig), pelo apoio financeiro.

\section{Referências}

ADAMS, R.P. Identification of essential oil components by gas chromatography/mass spectroscopy. $4^{\text {th }}$ ed. Carol Stream: Allured Publishing Corporation, 2007. 804p.

AMARAL, M.F.Z.J.; BARA, M.T.F. Avaliação da atividade antifúngica de extratos de plantas sobre o crescimento de fitopatógenos. Revista Eletrônica de Farmácia, v.2, p.5-8, 2005.

ATLAS do Tocantins: subsídios ao planejamento da gestão territorial. 3.ed. Palmas: Seplan, 2003. 49p.

BARBOSA, L.C.A.; PEREIRA, U.A.; MARTINAZZO, A.P.; MALTHA, C.R.A.; TEIXEIRA, R.R.; MELO, E.C. Evaluation of the chemical composition of Brazilian commercial Cymbopogon citratus (D.C.) Stapf samples. Molecules, v.13, p.1864-1874, 2008 .

BEZERRA, A.M.E.; NASCIMENTO JÚNIOR, F.T. do; LEAL, F.R.; CARNEIRO, J.G. de M. Rendimento de biomassa, óleo essencial, teores de fósforo e potássio de chambá em resposta à adubação orgânica e mineral. Revista Ciência Agronômica, v.37, p.124-129, 2006.

BLANK, A.F.; SILVA, P. de A.; ARRIGONI-BLANK, M. de F.; SILVA-MANN, R.; BARRETO, M.C. de V. Influência da adubação orgânica e mineral no cultivo de manjericão cv. Genovese. Revista Ciência Agronômica, v.36, p.175-180, 2005.

BRANT, R. da S.; PINTO, J.E.B.P.; BERTOLUCCI, S.K.V.; ALBUQUERQUE, C.J.B. Produção de biomassa e teor do óleo essencial de cidrão em função da adubação orgânica. Horticultura Brasileira, v.28, p.111-114, 2010.
CASTRO, H.G.; BARBOSA, L.C.A.; LEAL, T.C.A.B.; SOUZA, C.M.; NAZARENO, A.C. Crescimento, teor e composição do óleo essencial de Cymbopogon nardus (L.). Revista Brasileira de Plantas Medicinais, v.9, p.55-61, 2007.

CASTRO, H.G. de; FERREIRA, F.A.; SILVA, D.J.H. da; MOSQUIM, P.R. Contribuição ao estudo das plantas medicinais: metabólitos secundários. 2.ed. Viçosa: UFV, 2004. 113p.

CASTRO, H.G. de; PERINI, V.B. de M.; SANTOS, G.R. dos; LEAL, T.C.A.B. Avaliação do teor e composição do óleo essencial de Cymbopogon nardus (L.) em diferentes épocas de colheita. Revista Ciência Agronômica, v.41, p.308-314, 2010.

CORRÊA, R.M.; PINTO, J.E.B.P.; REIS, E.S.; COSTA, L.C.B.; ALVES, P.B.; NICULAN, E.S.; BRANT, R.S. Adubação orgânica na produção de biomassa de plantas, teor e qualidade de óleo essencial de orégano (Origanum vulgare L.) em cultivo protegido. Revista Brasileira de Plantas Medicinais, v.12, p.80-89, 2010.

COSTA, L.C. do B.; PINTO, J.E.B.P.; CASTRO, E.M. de; BERTOLUCCI, S.K.V.; CORRÊA, R.M.; REIS, É.S.; ALVES, P.B.; NICULAU, E. dos S. Tipos e doses de adubação orgânica no crescimento, no rendimento e na composição química do óleo essencial de elixir paregórico. Ciência Rural, v.38, p.2173-2180, 2008.

DEMUNER, A.J.; BARBOSA, L.C.A.; MAGALHÃES, C.G.; SILVA, C.J; MALTHA, C.R.A.; PINHEIRO, A.L. Seasonal variation in the chemical composition and antimicrobial activity of volatile oils of three species of Leptospermum (Myrtaceae) grown in Brazil. Molecules, v.16, p.1181-1191, 2011

DEUS, R.J.A.; ALVES, C.N.; ARRUDA, M.S.P. Avaliação do efeito antifúngico do óleo resina e do óleo essencial de copaíba (Copaifera multijuga Hayne). Revista Brasileira de Plantas Medicinais, v.13, p.1-7, 2011.

DONLAPORN, S.; SUNTORNSUK, W. Antifungal activities of ethanolic extract from Jatropha curcas seed cake. Journal of Microbiology and Biotechnology, v.20, p.319-324, 2010.

FIORI, A.C.G.; SCHWAN-ESTRADA, K.R.F.; STANGARLIN, J.R.; VIDA, J.B.; SCAPIM, C.A.; CRUZ, M.E.S.; PASCHOLATI, S.F. Antifungal activity of leaf extracts and essential oils of some medicinal plants against Didymella bryoniae. Journal of Phytopathology, v.148, p.483-487, 2000.

GARCIA, R.Á.; JULIATTI, F.C.; BARBOSA, K.A.G.; CASSEMIRO, T.A. Atividade antifúngica de óleo e extratos vegetais sobre Sclerotinia sclerotiorum. Bioscience Journal, v.28, p.48-57, 2012.

GONÇALVES, L.L.A.; BARBOSA, L.C.A.; AZEVEDO, A.A.; CASALI, V.W.D.; NASCIMENTO, E.A. Produção e composição do óleo essencial de alfavaquinha (Ocimum selloi Benth.) em resposta a dois níveis de radiação solar. Revista Brasileira de Plantas Medicinais, v.6, p.8-14, 2003.

KOFFI, K.; KOMLA, S.; CATHERINE, G.; CHRISTINE, R.; JEAN-PIERRE, C.; LAURENCE, N. In vitro cytotoxic activity of Cymbopogon citratus L. and Cymbopogon nardus L. essential oils from Togo. Bangladesh Journal of Pharmacology, v.4, p.29-34, 2009. 
MAHALWAL, V.S.; ALI, M. Volatile constituents of Cymbopogon nardus (Linn.) Rendle. Flavour and Fragrance Journal, v.18, p.73-76, 2003.

MARTINS, F.T.; SANTOS, M.H. dos; POLO, M.; BARBOSA, L.C. de A. Variação química do óleo essencial de Hyptis suaveolens (L.) Poit., sob condições de cultivo. Química Nova, v.29, p.1203-1209, 2006.

MONTANARI, R.M.; BARBOSA, L.C.A.; DEMUNER, A.J.; SILVA, C.J.; ANDRADE, N.J.; ISMAIL, F.M.D.; BARBOSA, M.C.A. Exposure to Anacardiaceae volatile oils and their constituents induces lipid peroxidation within food-borne bacteria cells. Molecules, v.16, p.9728-9740, 2012.

NASCIMENTO, J.C.; BARBOSA, L.C.A.; PAULA, V.F.; DAVID, J.M.; FONTANA, R.; SILVA, L.A.M.; FRANÇA, R.S. Chemical composition and antimicrobial activity of essential oils of Ocimum canum Sims. and Ocimum selloi Benth. Anais da Academia Brasileira de Ciências, v.83, p.787-799, 2011.

PASSOS, J.L.; BARBOSA, L.C.A.; DEMUNER, A.J.; ALVARENGA, E.S.; SILVA, C.M.; BARRETO, R.W. Chemical characterization of volatile compounds of Lantana camara L. and L. radula Sw. and their antifungal activity. Molecules, v.17, p.11447-11455, 2012.

PERINI, V.B. de M.; CASTRO, H.G. de; SANTOS, G.R. dos; AGUIAR, R.W. de S.; LEÃO, E.U.; SEIXAS, P.T.L. Avaliação do efeito curativo e preventivo do óleo essencial do capim citronela no controle de Pyricularia grisea. Journal of Biotechnology and Biodiversity, v.2, p.23-27, 2011.

RASOOLI, I.; REZAEI, M.B.; ALLAMEH, A. Growth inhibition and morphological alterations of Aspergillus niger by essential oils from Thymus eriocalyx and Thymus x-porlock. Food Control, v.17, p.359-364, 2006.

REIS, G.G.; PEISINO, A.L.; ALBERTO, D.L.; MENDES, M.F.; CALÇADA, L.A. Estudo do efeito da secagem em convecção natural e forçada na composição do óleo essencial da citronela (Cymbopogon nardus). Revista Brasileira de Plantas Medicinais, v.8, p.47-55, 2006.
RIBEIRO JÚNIOR, J.I.; MELO, A.L.P. Guia prático para utilização do SAEG. Viçosa: UFV, 2009. 287p.

SALES, J.F.; PINTO, J.E.B.P.; BOTREL, P.P.; SILVA, F.G.; CORREA, R.M.; CARVALHO, J.G. de. Acúmulo de massa, teor foliar de nutrientes e rendimento de óleo essencial de hortelã-do-campo (Hyptis marrubioides Epl.) cultivado sob adubação orgânica. Bioscience Journal, v.25, p.60-68, 2009.

SCHWAN-ESTRADA, K.R.F.; STANGARLIN, J.R.; CRUZ, M.E.S. Uso de plantas medicinais no controle de doenças de plantas. Fitopatologia Brasileira, v.28, p.554-556, 2003.

SEIXAS, P.T.L.; CASTRO, H.C.; SANTOS, G.R.; CARDOSO, D.P. Controle fitopatológico do Fusarium subglutinans pelo óleo essencial do capim-citronela (Cymbopogon nardus L.) e do composto citronelal. Revista Brasileira de Plantas Medicinais, v.13, p.523-526, 2011.

SILVA, C.J.; BARBOSA, L.C.A.; DEMUNER, A.J.; PINHEIRO, A.L.; DIAS, I.; ANDRADE, N.J. Chemical composition and antibacterial activities from the essential oils of myrtaceae species planted in Brazil. Química Nova, v.33, p.104-108, 2010.

SINGH, H.; GUPTA, V.K.; RAO, M.M.; SANND, R.; MANGAL, A.K. Evaluation of essential oil composition of Cymbopogon spp. International Journal of Pharma Recent Research, v.3, p.40-43, 2011.

SOUZA JÚNIOR, I.T.; SALES, N.L.P.; MARTINS, E.R. Efeito fungitóxico de óleos essenciais sobre Colletotrichum gloeosporioides, isolado do maracujazeiro amarelo. Biotemas, v.22, p.77-83, 2009.

TRONGTOKIT, Y.; RONGSRIYAM, Y.; KOMALAMISRA, N.; APIWATHNASORN, C. Comparative repellency of 38 essential oils against mosquito bites. Phytotherapy Research, v.19, p.303-309, 2005.

WONG, K.K.Y.; SIGNAL, F.A.; CAMPION, S.H.; MOTION, R.L. Citronella as an insect repellent in food packaging. Journal of Agricultural and Food Chemistry, v.53, p.4633-4636, 2005 .

$\overline{\text { Recebido em } 2 \text { de abril de } 2012 \text { e aprovado em } 23 \text { de outubro de } 2012}$ 